Vol. 6, No. 2, 2020

\author{
Andrij Dzyubyk ${ }^{1}$, Ihor Nazar ${ }^{2}$, Liudmyla Dzyubyk ${ }^{3}$ \\ ${ }^{1}$ Department of Oil and Gas Engineering and Welding, Lviv Polytechnic National University, \\ 12, S. Bandera Str., Lviv, Ukraine, e-mail: andrii.r.dziubyk@lpnu.ua, ORCID 0000-0003-2091-171X \\ ${ }^{2}$ Department of Oil and Gas Engineering and Welding, Lviv Polytechnic National University, \\ 12, S. Bandera Str., Lviv, Ukraine, e-mail: hor.b.nazar@lpnu.ua, ORCID 0000-0003-2592-3592 \\ ${ }^{3}$ Department of Technical Mechanics and Dynamics of Machines, Lviv Polytechnic National University, \\ 12, S. Bandera Str., Lviv, Ukraine, e-mail: liudmyla.v.dziubyk@lpnu.ua, ORCID 0000-0001-6942-9436
}

\title{
FEATURES OF REPAIR WELDING OF POWER HYDROCYLINDER ELEMENTS
}

Received: March 18, 2020 / Revised: April 22, 2020 / Accepted: September 30, 2020

C Dzyubyk A., Nazar I., Dzyubyk L., 2020

\begin{abstract}
At present, the use of power hydraulic cylinders is an integral part of most industrial equipment. They provide translational and horizontal movements, replacement of goods, fixation, etc. These devices are necessary elements of the equipment where application of the corresponding level of effort is applied. Often hydraulic cylinders are created specialized to perform certain types of work. It should be noted that part of the elements of the power cylinder in the manufacture is combined with welding. Such integral connections provide rigidity of installation, tightness of a design, fatigue strength at multicycle loadings.

Difficult operating conditions, significant workloads, the presence of various external factors often leads to the destruction of individual elements of the cylinder. At the same time, the cost of repairing equipment that involves replacement with new power devices is quite high. This causes the implementation of repair and restoration work carried out at specialized enterprises. However, in the case of repairs, there are often a number of problems that require prompt resolution in the production environment. These should include the provision of basic materials with similar physical and chemical properties, the establishment of welding modes, the selection of the necessary welding materials, the use of appropriate techniques for conducting the arc process, etc. Therefore the repaired welded design of the case of the power hydraulic cylinder needs additional studying for weldability of separate elements among themselves, formation of a zone of thermodeformation influence. In general, the repaired hydraulic cylinder should meet the installation operating requirements depending on the purpose.

The design of the considered hydraulic cylinder of the press installation is rather technological from the point of view of maintenance of automation of welding process. It contains long welds of a simple ring configuration. At the same time, the significant linear dimensions and the presence of a cylindrical surface cause some complexity in the implementation of processes. The construction material of the power hydraulic cylinder is low-carbon low-alloy steels. The analysis of technological weldability indicates a tendency to crack due to the thermal cycle of welding.

The simulation of welds of the power hydraulic cylinder is performed in the work. The number of rollers was taken into account when obtaining butt welds. A comparative analysis of different electrode materials with different doping systems is done. The most applicable welding materials by chemical composition and properties of the weld metal are determined.

According to the literature data and the results of comparative analysis, the optimal range of cooling rate of the main material of the hydraulic cylinder was established. The properties and structure of the zone of thermal influence of the butt welds of the power hydraulic cylinder have been studied.
\end{abstract}




\section{Andrij Dzyubyk, Ihor Nazar, Liudmyla Dzyubyk}

The magnitude of deformations and stresses caused by the thermal cycle of welding of the shell structure of the hydraulic cylinder liner is investigated. The admissible parameters of the zone of plastic deformations during butt welding are determined.

Keywords: power hydraulic cylinder, welding modes, deformations of the hydraulic cylinder liner, welding electrode wires, repair of the hydraulic cylinder.

\section{Introduction}

The research features of realization of welding process at repair of the power hydraulic cylinder which is applied in the press equipment is carried out in work. Design analysis shows that different types of welds which are used in this case. The configuration, cross section and length of the seams are also different. It is important to ensure the correct choice of electrode materials. The chemical composition of the base and filler metals, the technique of making the joints and the cross section of the weld should be taken into account. Welding of the back cover to the sleeve $(\varnothing 140 \mathrm{~mm})$ is realized by an annular weld of the butt weld. Here it is important to take into account the probable intensive heat dissipation, which can lead to hardening of the seam areas. Therefore, the study of the properties of the thermal zone is an urgent task. The wall thickness of the power cylinder liner is quite significant and in this case is $10 \mathrm{~mm}$. The total length of the assembled construction of the sleeve and cover is $687 \mathrm{~mm}$. Often the back cover can be larger and contain an additional fastener in the form of a threaded connection. This reduces residual deformation due to the thermal cycle of welding.

\section{Object and subject of research}

The object of research is the elements of the power cylinder, which are subjected to repair welding. It is also necessary to carry out a comprehensive study of the characteristics of the obtained welded joints. Therefore, the subject of the research is welded butt joints of regenerative power cylinders.

\section{Purpose and objectives of the study}

The purpose of the performed researches is to provide the established operational and technological properties of connections of power hydraulic cylinders after repair welding. The main tasks that are set in the work should include: study of the chemical composition of the weld metal of the obtained welded joints for different welding materials; study of the main material of the power hydraulic cylinder of the press equipment in order to establish the optimal cooling rates; establishment of the structure and mechanical properties of the material of the thermal zone of the base metal; study of the peculiarities of the formation of residual stresses and strains during welding.

\section{The practical significance of the obtained results}

A comprehensive approach to the implementation of repair welding of power hydraulic cylinders is proposed, which takes into account the properties of the base metal of the elements, the characteristics of the weld metal and the zone of thermal impact. It is shown that the value of welding deformations in the performance of annular seams may exceed the allowable value of technical requirements.

\section{Analysis of Literary Sources}

Operation of power hydraulic cylinders is characterized by difficult conditions and significant workloads, under the combined action of various external factors [1]. All this often leads to the destruction of individual elements of the hydraulic cylinders. The cost of replacing new equipment is generally higher, compared to the implementation of repair and restoration processes [2]. In this case, the performance of repair welding of high-strength steels requires consideration of a number of specific factors [3]. All of them are installed separately, but it is necessary to use the obtained results in the subsequent development of repair welding technology [2], [4]. In particular, the initial parameter for assessing the weldability of the base material is its chemical composition and structure [5], [6]. This is an important, but mostly insufficient stage, because it is necessary to take into account the "sensitivity" of the material to the thermal cycle of 


\section{Features of Repair Welding of Power Hydrocylinder Elements}

welding [7], [8]. The chosen design scheme of heat distribution should take into account the conditions of the process, the properties of the base metal and the structural dimensions of the welded joint [8], [9]. As a result, it is possible to assess not only the tendency of steel to crack, but also the structural-phase composition and mechanical properties of the metal in the zone of thermal impact of the joint [10], [11].

The chemical composition of the weld is pre-modeled taking into account the applied welding method, the amount of penetration, the type of welds, etc. [8], [12]. This makes it possible to investigate the uniformity of the welded joint and its crack resistance in the area of the weld metal. Due to the uneven chemical composition, it is possible to form areas with structural inhomogeneity, which can further lead to local defects such as cracks [11]. The design of the cylinder liner indicates a complex stress in the vicinity of the weld with a ring seam [13]. Often the magnitude of residual deformations leads to the use of special measures to prevent or compensate from them [14]. This is due to the formation of residual deformations, which can further impede the movement of the piston with the rod. Therefore, the preliminary numerical analysis [15], [16] of such values is important at the design stage of repair welding technology.

\section{Results and Discussion}

Steel of grade St 37.4 - 1.0255 - EN 10217-1 was used as the main material for the production of hydraulic cylinder elements. It is widely used in hydraulic engineering and products with special strength requirements (high working pressures, etc.). Evaluation of weldability of steel was carried out on the basis of calculating carbon equivalent $\left(C_{\text {equiv }}\right.$ ), which takes into account the influence of not only carbon but also other alloying materials on the tendency to form hardening structures under the action of thermal welding cycle [5], [7]-[12]. It is established that steel is characterized by rather limited weldability. The calculated indicator $\left(C_{\text {equiv }}\right)$ slightly exceeds the maximum allowable level $\left(C_{\text {equiv }} \approx 0.48 \%\right)$. This way, the possibility of hardening structures formation and the probability of cold cracking should be taken into account. Therefore, the implementation of repair welding of the power hydraulic cylinder of the press equipment requires additional analysis of individual operations and technological transitions. This will allow to solve the tasks set in the work and to create technological recommendations for the improvement of repair and restoration welding operations of the power hydraulic cylinder of the press equipment.

Modeling of chemical composition of welds. To study the chemical composition of the welded rollers, an approach was used that takes into account the proportion of base metal and welding electrode wire at the established transition coefficients of alloying elements, which are presented in the literature [5], [6], [8], [12]. It is established that the welded joint at the place of fastening of a back cover to a sleeve of the hydraulic cylinder is exposed to the greatest loadings. Therefore, the chemical composition of the weld of this type of joint was modeled in the work. V is used here - a similar design of the edges of the welded joints of the sleeve and the back cover. Implementation of the welding process is carried out in the lower position. The general type of welded joint with the approximate limits of penetration of the base metal and the formation of the weld is shown in Fig. 1. In particular, the features of the formation of the root roller and the subsequent production of the filling seam are presented. The latter contains particles of electrode and base metals, as well as the root seam.

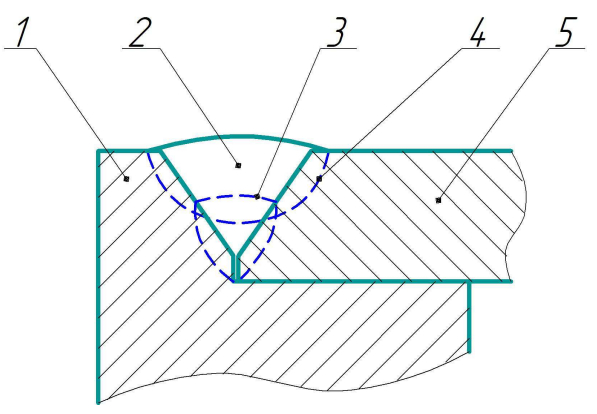

Fig. 1. Geometry of the welded connection of the rear cover and the sleeve of the power cylinder: 1, 5 - rear cover and sleeve; 2 - welded roller; 3, 4-penetration zones for root and filling joints, respectively

Approaches were used to perform the calculations, which allow to establish the chemical composition of each pass [6]-[9], [12]. If the chemical composition of all parts of the joint (electrode wire, 


\section{Andrij Dzyubyk, Ihor Nazar, Liudmyla Dzyubyk}

sleeve and back cover) is different, the share of each of them in the formation of the weld metal should be taken into account. Then the chemical composition of a single roller can be written by the expression:

$$
\mathrm{E}_{w r}=\eta \cdot \mathrm{E}_{f w} \cdot \mathrm{A}_{f w}+\sum_{i=1}^{n} \mathrm{E}_{i} \cdot S_{i}
$$

where $\mathrm{E}_{w r}$ - content of the element in the welded roller; $\eta$ - transition factor of the element from the filler wire; $\mathrm{E}_{f w}$ - content of the element in the filler wire; $\mathrm{A}_{f w}$ - the proportion of filler wire in the weld; $\mathrm{E}_{i}$ - the content of the element in the $i$-th part of the joint of the hydraulic cylinder; $\Sigma_{i}$ - the proportion of metal of the $i$-th part of the joint of the hydraulic cylinder in the weld.

This way you can get the calculation formulas for establishing the chemical composition for each pass of the joint of the rear cover and the sleeve. For the case of their identical composition, you can write the following:

- chemical composition of the root suture:

$$
\mathrm{E}_{r r}=\eta \cdot \mathrm{E}_{f w} \cdot \mathrm{A}_{w . r w}+\mathrm{E}_{e m} \cdot B_{b w},
$$

where $\mathrm{E}_{r r}$ - the content of the element in the root roller; $\eta$ - transition factor of the element from the filler wire; $\mathrm{E}_{f w}$ - content of the element in the filler wire; $\mathrm{A}_{w . r w}$ - the proportion of filler wire in the root weld; $\mathrm{E}_{e m}$ - the content of the element in the main metal of the cylinder; $B_{b w}-$ the proportion of base metal in the root weld;

- chemical composition of the filling seam:

$$
\mathrm{E}_{f l w}=\eta \cdot \mathrm{E}_{f w} \cdot \mathrm{A}_{p . f w}+\mathrm{E}_{e m} \cdot B_{1 . b m w}+\mathrm{E}_{r r} \cdot B_{2 . r m f},
$$

where $\mathrm{E}_{f l w}$ - content of the element in the filler weld; $\mathrm{A}_{p . f w}$ - proportion of filler wire in the weld; $B_{1 . b m w}$ - proportion of base metal in the weld; $B_{2 . r m f}$ - proportion of root weld metal in the filler weld.

As a result of substituting the content of chemical elements in expressions (2) and (3) it is possible to obtain an approximate value of the chemical composition of the weld. This will allow to evaluate its composition and mechanical properties, as well as to make recommendations for the use of a welding electrode wire in the designed process.

It is important to establish the transition factor and particles of chemical elements in the weld metal. To do this, we use the recommendations of the specialized literature [5], [6], [8], [12], [17] and the data of expert assessment of such indicators when welding in a protective gas environment. In particular, it can be assumed that the conversion factor when using a carbon-argon mixture will be $\eta=0.75$. For a root weld, the proportion of base metal in the weld roller will be commensurate with the electrode wire. This appears due to the presence of blunting in the root of the weld and the substrate in the form of a back cover. Therefore, we accept the following: $\mathrm{A}_{\kappa . \partial p}=b_{\kappa}=0.5$.

The surfacing of the filling roller has its own characteristics. This involves not only the base and filler metals, but also the root weld metal. Therefore, there will be more metal particles here. Taking as a basis the above considerations we obtain the following. The influence of filler metal on the formation of the seam will be greater, because it is necessary to melt the development of the edges. The melting of the metal edges is slightly larger, and the root roller is smaller. For the following calculations we accept the following calculated coefficients: $\mathrm{A}_{p . f w}=0.4 ; B_{1 . b m w}=0.35 ; B_{2 . \mathrm{rmf}}=0.25$.

It should be noted that the execution of the first pass in its characteristics will be close to the execution of corner seams for welding fittings - here welding takes place in one pass.

Investigation of the chemical composition of the seam for different welding wires. Let's consider the choice of welding materials for the case of repair welding of the power cylinder in the environment of protective mixtures. The following requirements were taken into account: the chemical composition of the weld wire must contain similar alloying elements or similar in metallurgical and physicochemical effects; the selected wire must be oriented to the application for a certain class of steels; the mechanical properties of the weld metal must not be lower than the base metal of the hydraulic cylinder. 


\section{Features of Repair Welding of Power Hydrocylinder Elements}

Taking into account the above criteria, electrode wires of OK ARISTOROD 13.08, OK ARISTOROD 13.09, OK ARISTOROD 13.16, OK AUTROD 12.51 brands were selected for analysis. Wire OK AUTROD 12.51 in its composition is close to the recommended by most specialized organizations and literature sources [5], [12], [17] domestic analogue - wire 08Mn2Si.

Below (Table 1) there are the results of calculations in accordance with expressions (2) and (3) for cases of welding in two passes. The results of the corresponding content of legislative chemical elements in electrode wires and application of the capital are systematized here. There is a gradual decrease in alloying elements in the root and filling joints. At the same time in the filling seam they are the least in comparison with steel of the hydraulic cylinder (St 37.4 - 1.0255 - EN 10217-1), approximately twice. However, given the small size of the weld compared to the rest of the hydraulic cylinder design, the effect of this reduction in alloying elements will be negligible on the overall performance of the weld.

Table 1

The results of modeling the chemical composition of the weld metal between the rear cover and the cylinder liner

\begin{tabular}{|c|c|c|c|c|c|c|}
\hline Welded roller & Mn & Mo & C & Si & Ni & Cr \\
\hline \multicolumn{7}{|c|}{ welded wire OK ARISTOROD 13.08 } \\
\hline root & 1.268 & 0.216 & 0.117 & 0.400 & 0.169 & 0.165 \\
\hline filling & 1.271 & 0.223 & 0.115 & 0.402 & 0.162 & 0.158 \\
\hline \multicolumn{7}{|c|}{ welded wire OK ARISTOROD 13.09} \\
\hline root & 1.009 & 0.209 & 0.115 & 0.404 & 0.165 & 0.176 \\
\hline filling & 0.999 & 0.215 & 0.113 & 0.406 & 0.158 & 0.170 \\
\hline welded wire OK ARISTOROD 13.16 \\
\hline root & 0.750 & 0.228 & 0.118 & 0.362 & 0.188 & 0.638 \\
\hline filling & 0.728 & 0.235 & 0.115 & 0.363 & 0.182 & 0.654 \\
\hline root & 1.148 & 0.040 & 0.109 & 0.494 & 0.150 & 0.150 \\
\hline filling & 1.145 & 0.038 & 0.107 & 0.501 & 0.142 & 0.142 \\
\hline
\end{tabular}

Comparative analysis of the obtained results of calculation of the chemical composition of welds and the base metal has a characteristic for all wires reduction of carbon content compared to the base metal. In this case, it has a positive effect and provides the necessary crack resistance of the weld metal. The carbon content is the lowest for OK AUTROD 12.51 wire $(0.109 \%$ and $0.107 \%)$ in the root and filler joints.

The content of manganese, which provides the required strength of the material is almost the same as the base metal for the electrode wire OK ARISTOROD $13.08(1.268 \%$ and $1.271 \%)$ in the root and filler joints, respectively. This content is slightly lower for OK ARISTOROD 13.09 and OK ARISTOROD 13.16 wires. For OK AUTROD 12.51 electrode wire, the manganese content is higher than the base metal and is $1.148 \%$ and $1.145 \%$ in the root and filler joints. Silicon, which actively influences the deoxidation reactions in the weld metal and increases the strength of the latter, is also most provided by the use of electrode wire brand OK AUTROD $12.51(0.494 \%$ and $0.501 \%)$. For the rest of considered wires, the silicon content in the range of $0.362 \% \ldots 0.406 \%$ is observed.

The content of elements such as nickel and chromium for all used electrode wires is approximately the same and ranges from $0.142 \%$ to $0.176 \%$. The exception is the electrode wire OK ARISTOROD 13.16 , which has a higher content of chromium in the initial state $(1.3 \%)$, and therefore three times higher than the average values of the content of this element for other electrode materials used. The molybdenum content is the smallest in the weld metal wire OK AUTROD 12.51 ( 0.040 and $0.038 \%$, respectively). This is due to its absence in the original wire alloying system. Here, the supply of molybdenum to the weld metal occurs only from the base metal. For the rest of the electrode wires, the average molybdenum content from $0.216 \%$ to $0.235 \%$ is provided. 


\section{Andrij Dzyubyk, Ihor Nazar, Liudmyla Dzyubyk}

Therefore, in the case of welding the back cover to the sleeve of the power cylinder of the press equipment, it is advisable to use a wire that provides a lower carbon content, and the strength compensation is due to alloying elements such as manganese and silicon. The content of elements having a metallurgical effect on the fineness of the structure and corrosion resistance of the weld metal in this case is partially provided. It should also be noted that the electrode wire must be low, and therefore be economically feasible. Therefore, in this case it is recommended to use a wire of the OK AUTROD 12.51 brand, domestic analog - a wire 08Mn2Si.

Establishing optimal cooling intervals during repairs. To establish the appropriate welding technology of the power cylinder elements, it is necessary to perform an analysis to ensure the crack resistance of welded joints. An important step is to study the cooling rate of the material and perform a comparative analysis with the values recommended in the literature. The most widespread issue is the allowable cooling rates of the material, the establishment of the optimal running energy of welding, etc. disclosed in special literature [7], [8], [12], [17]. However, with regard to the steel (base material) used to make the hydraulic cylinder, the authors were unable to establish such data.

The following approach was used to determine the approximate value of the allowable cooling rate of the base metal of the welded joint of the hydraulic cylinder. It provides for the establishment of such indicators for approximate physicochemical properties of steels, followed by comparative analysis. Estimation was used not only for chemical composition, but also for mechanical properties. The last one is true because ensuring the uniformity of the weld material requires the following results.

The analysis of the main material of the power hydraulic cylinder showed that in this case the closest in chemical composition are low-alloy steels of grades $15 \mathrm{KhSiNCu}$ and $15 \mathrm{KhSiNM}$. They belong to the class of chromium-nickel and chromium-manganese-nickel materials, which are close to the used basic material of the hydraulic cylinder.

Comparative analysis of the chemical composition shows that the carbon content in steel $15 \mathrm{KhSiNCu}$ is slightly higher, but the silicon content is close to the base metal. The manganese content is slightly lower compared to steel St 37.4 - 1.0255 - EN 10217-1. The content of chromium and nickel exceeds similar indicators of the base material. Also, in steel $15 \mathrm{KhSiNCu}$ there is doping with molybdenum, which has a positive effect on the performance of the material. For steel $15 \mathrm{KhSiNM}$ is characterized by coincidence in the content of carbon, silicon and manganese, but the content of alloying elements such as molybdenum, chromium, nickel is slightly higher.

Comparative analysis of the mechanical characteristics of both steels and the main material of the hydraulic cylinder indicates the closeness of the established values. Both steels $15 \mathrm{KhSiNCu}$ or $15 \mathrm{KhSiNM}$ are delivered after rolling and do not require additional heat treatment.

The source [7] gives the approximate values of the allowable cooling rate of the seam areas for these steels. Also, here it is specified on what technological breakdown results are received. The thickness of the test specimens is close to the main material of the power cylinder liner, which also ensures the adequacy of the result. In steel $15 \mathrm{KhSiNM}$ the maintenance of structure of hardening like martensite, within $20 \%$, without negative consequences on operational properties is allowed. The low-alloy steels selected for comparative analysis are close in terms of the optimal range of cooling rates. In order to ensure the required performance characteristics, a conservative approach was used. It will be used to narrow the optimal range of cooling rates $\left(\Delta \omega_{\text {orc }}\right)$. We accept this value within 1.8 to $9.0 \mathrm{grad} / \mathrm{sec}$.

The obtained results make it possible to set the allowable parameters of the welding mode of the used welded joints, the need to implement preheating before welding. This should take into account the technique of welding, which is also an important factor. In particular, when making two-layer connections, the possibility of auto-heating from pre-applied rollers is realized. It is important to ensure the continuity of welding to avoid cooling of the seam areas before applying the next roller.

Investigation of the structure and mechanical properties of welded joints. To study the properties of the obtained welded joints of the power hydraulic cylinder of the press equipment, it is necessary to set the value of the cooling rate of the metal of the thermal zone. To calculate the cooling rate $\left(\omega_{\text {orc }}\right)$ we use the following formula (4), which is recommended by the special literature [8], [9]: 


$$
\omega_{\text {orc }}=2 \cdot \pi \cdot \lambda \cdot \varpi \frac{\left(\mathrm{T}_{k}-\mathrm{T}_{n}\right)^{2}}{q / V_{\text {weld }}},
$$

where $\mathrm{T}_{k}$ - controlled temperature of maximum heating; $\mathrm{T}_{n}-$ initial temperature of welded elements; $q / V_{\text {weld }}$ - running energy of welding; $\lambda$ - thermal conductivity; $\Phi$ - parameter that takes into account the welding mode and the thickness of the structure.

The parameter $\varpi$ is determined by a special nomogram after calculating the corresponding dimensionless criterion $\left(\frac{1}{\theta}\right)$ determined by the formula [8]:

$$
\frac{1}{\theta}=-\frac{2 \cdot q / V_{\text {weld }}}{\pi \cdot \delta^{2} \cdot c \rho \cdot\left(\mathrm{T}_{k}-\mathrm{T}_{n}\right)},
$$

where $\delta$ - the thickness of the elements; $c \rho$ - specific heat.

The butt weld according to the developed technology involves the implementation of two layers. The parameters of the welding mode are accepted in this case taking into account the recommendations for the electrode wire OK AUTROD 12.51 [18] and the recommendations of the special literature [5], [8]-[12], [17]. We accept welding current $\left(I_{\text {weld }}\right)$ which is equal to $280 \mathrm{~A}$, the arc voltage $\left(U_{a v}\right) 27 \mathrm{~V}$, and welding speed $\left(V_{\text {weld }}\right) 21 \mathrm{~m} /$ hour. Then the dimensionless criterion $\left(\frac{1}{\theta}\right)$, according to (5), will be equal to 2.25 .

The controlled temperature $\left(\mathrm{T}_{\kappa}\right)$ is considered to be equal to $550^{\circ} \mathrm{C}$ taking into account the critical values of the characteristic structural transformations in the steel being investigated [7], [8]. The initial temperature while imposing the first layer is equal to $20^{\circ} \mathrm{C}$. Then the dimensionless parameter $(\varpi)$, is defined, according to the special nomogram (Fig. 2), in this case will be 0.275 .

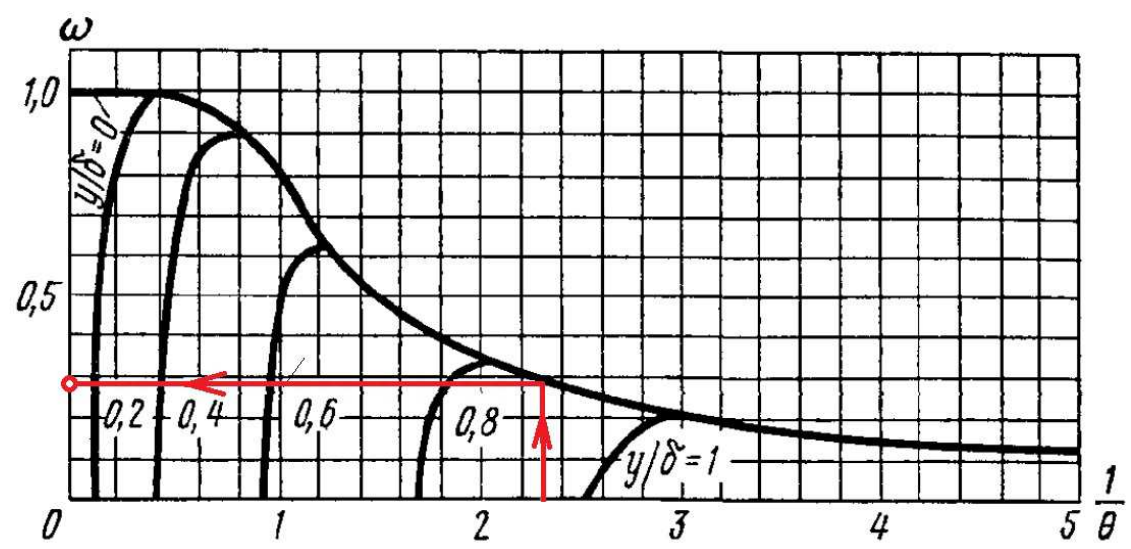

Fig. 2. Determination of dimensionless parameter $(\varpi)$ according to a special nomogram [8] when welding the butt joint of the power cylinder

We assume that immediately after the execution of the first roller $\left(\omega_{\text {orc }}^{I}\right)$ welding of the second roller $\left(\omega_{\text {orc }}^{I I}\right)$ is performed. Therefore, there is an effect of "auto-heating" from the previous action of the welding arc. The initial $\left(\mathrm{T}_{n}\right)$ temperature for the second roller will be approximate $200^{\circ} \mathrm{C}$. Applying expression (4) we obtain that $\omega_{o r c}^{I}=19.3 \mathrm{grad} / \mathrm{sec}, \omega_{\text {orc }}^{I I}=8.4 \mathrm{grad} / \mathrm{sec}$ for root and filler welds, respectively.

That is, the execution of the first roller butt joint is characterized by intensive heat dissipation. In this case, the cooling rate exceeds the allowable, which is recommended for the brand of steel. However, the execution of the next roller provides a reduction of this speed to an acceptable value and a 


\section{Andrij Dzyubyk, Ihor Nazar, Liudmyla Dzyubyk}

corresponding redistribution of the structural-phase composition. The values of cooling rates were plotted on the structural diagram of $15 \mathrm{KhSiNM}$ steel (Fig. 3). The obtained results allow to perform an approximate assessment of the structure in the zone of thermal influence of the welded joint.

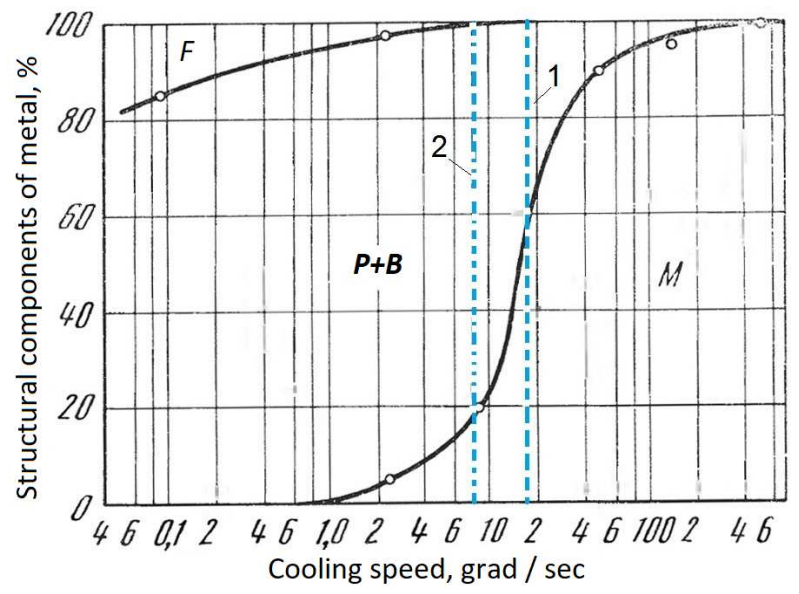

Fig. 3. Diagram for the establishment of structural transformations in the butt weld of the power cylinder [7]: 1,2 - the structure of the suture area when performing the first and second rollers

Therefore, when performing the first roller, a mixture of perlite and bainite $(\mathrm{P}+\mathrm{B})$ and martensite (M) is observed in the material. That is, structures that are characterized by increased strength but reduced ductility. Here the mixture of $\mathrm{P}+\mathrm{B}$ is about $40 \%$, respectively, martensite is about $60 \%$. This significantly exceeds the permissible level. Therefore, it is important to either heat the weld material or make the next pass until the previous roller has cooled. This case should be applied at repair welding of a back cover and a sleeve of the power hydraulic cylinder. The application of the second roller provides a much lower rate of cooling and obtaining ferrite, perlite-bainite and martensitic structures. It can be found that the content of ferrite is $1.4 \%$, perlite-bainite mixture $80.8 \%$, and martensite component $17.8 \%$. Therefore, the content of martensite does not exceed the critical value of $20 \%$.

To study the mechanical properties of welded joints, it is advisable to use the appropriate graphical dependences (Fig. 4) [7]. This establishes a relationship between the cooling rate and the basic mechanical characteristics for each of the rollers. Both states of the base metal (first and second rollers) differ from the original (left part in Fig. 4) due to the thermal cycle of welding. When performing the first, main, roller there is an increase in hardness, tensile strength and decrease in ductility (especially relative elongation). However, the application of the second roller slightly changes these characteristics, increases the ductility and decreases the strength properties. These results indicate the provision of the required strength characteristics of the weld without additional heat treatment, with the recommended technique of welding.

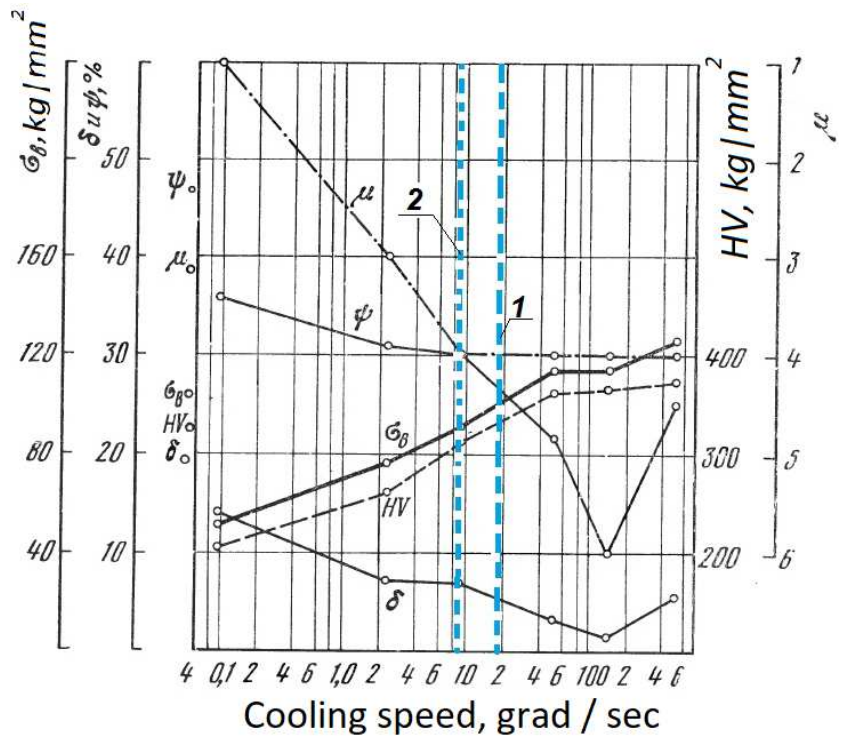

Fig. 4. Determination of mechanical characteristics in the butt weld [7]:

1,2 - cooling rate when performing the first and second rollers 


\section{Features of Repair Welding of Power Hydrocylinder Elements}

Modeling of stress-strain state in annular seams. The analysis showed that during the repair welding of the power hydraulic cylinder there are significant residual welding deformations. Therefore, the design of the rear cover involves the formation of a reinforcing end section, which ensures the deformation of the body of the sleeve in the area where the piston moves with the rod (Fig. 1).

The study of the amount of deformation during welding of a cylindrical element with a ring weld is performed below. Analysis of the features of deformation of cylindrical structures showed the following. For preliminary assessment of the size and nature of the welding stress-strain state of the hydraulic cylinder liner, the results of ring seam modeling can be used [16].

A mathematical machine was used for research, which is widely represented in the special literature [13]-[16]. Here, a computational method is used, which is based on the use of information about the nature and magnitude of metal shrinkage due to the thermal cycle of welding. In this case, the calculation makes it possible to obtain the desired values also in areas that are not fully sufficiently studied. Fig. 5 shows the deflection of the shell in the vicinity of the annular weld. Here on the $y$-axis is plotted the magnitude of the deflections $(W)$ in the shell after welding, and on the abscissa the distance $(l)$ from the axis of the weld.

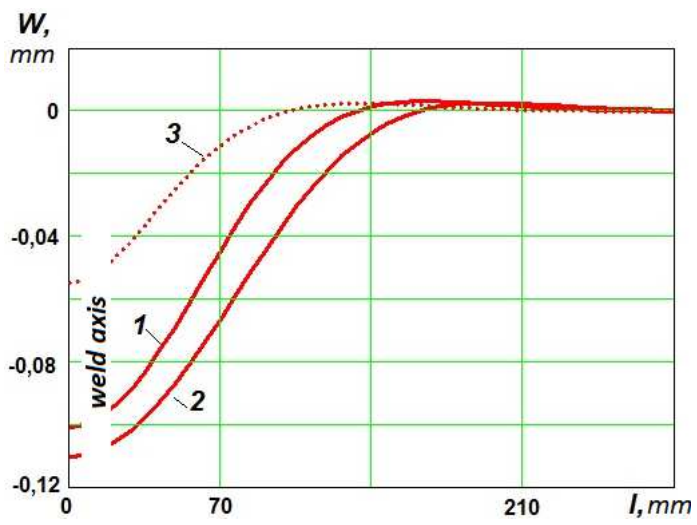

Fig. 5. Calculation of the deflection in the vicinity of the annular weld of the sleeve: 1,2 - approximate range of deflections when using arc methods; 3 - permissible deviations according to technical conditions

According to the obtained results, the largest values of deformations are achieved on the axis of the weld. Depending on the set width of plastic deformations, the deflection can be on the axis of the weld from $0.101 \mathrm{~mm}$ to $0.115 \mathrm{~mm}$ when performing the welding process. The magnitude of the deflection decreases rapidly with distance from the axis of the weld. At a distance that is approximately equal to the diameter of the cylinder liner, it is in both cases close to zero. Next, there is a slight back bend of the shell (convexity), at a distance of $140 \mathrm{~mm}$ to $200 \mathrm{~mm}$ relative to the axis of the weld. With further distance from the axis of the weld deflections become equal to zero.

Taking into account the established requirements for the accuracy of assembly and manufacture of the power hydraulic cylinder of the press equipment, the deflections from the welding cycle exceed the allowable values. In particular, according to the technical conditions, the landing is used, which provides for the accuracy of mutual assembly of elements with a deviation from 0 to $-0.054 \mathrm{~mm}$. That is, at a distance of approximately $70 \mathrm{~mm}$ relative to the axis of the weld, the requirements for tolerances are established. The study showed that for the established technical conditions it is necessary that the amount of welding plastic deformation does not exceed $20 \mathrm{~mm}$. In this case, the possible deviations will be within the tolerance $(0.054 \mathrm{~mm})$. These conditions (small size of the zone of plastic deformation) are possible only with the use of special welding techniques that minimize the thermal impact of the process. Such approaches require additional investment in the technological process of repair welding of the power hydraulic cylinder. Otherwise, the use of a rear cover with increased tail stiffness is necessary and appropriate. This makes it possible to ensure high-quality mutual assembly, and the threads on the cover and sleeve create additional fastening, while achieving the required rigidity of the structural element.

The calculations of residual welding stresses showed the following. On the inner surface of the hydraulic cylinder liner, the axial and annular stresses at the seam are tensile, but at a distance of up to $50 \mathrm{~mm}$ they fall to zero. On the outer surface, the axial stresses are compressive, and the ring stresses are close to zero. The value of maximum stresses does not exceed the yield strength. The greatest stresses are observed around the axis of the weld and decrease with distance from it. 


\section{Andrij Dzyubyk, Ihor Nazar, Liudmyla Dzyubyk}

\section{Conclusions}

The substantiation of electrode materials on the chemical composition of the weld and the obtained properties of the weld metal is performed. The set optimal range of cooling rate of the main material of the hydraulic cylinder is $1.8 \ldots 9.0 \mathrm{grad} / \mathrm{sec}$. The properties of the metal of the zone of thermal influence of the applied butt welds are investigated. The structural-phase composition at performance of two-pass seams is studied. The strength and plasticity characteristics of the obtained welded joints are determined. A study of the magnitude of displacements and stresses due to the thermal cycle of welding of the annular seam of the cylinder liner.

\section{References}

[1] V. O. Fedorets, et al., Hidropryvody ta hidropnevmoavtomatyka [Hydraulic Drives and Hydraulic and Pneumatic Automation]. Kyiv, Ukraine: Vyshcha shkola Publ., 1995. [in Ukrainian].

[2] I. B. Nazar, A. R. Dziubyk, A. A. Voitovych, Tekhnolohichni protsesy vidnovlennia detalei mashyn ta ahrehativ [Technological processes of repair of machine parts and assemblies]. Drohobych, Ukraine: Posvit Publ., 2020. [in Ukrainian].

[3] V. M. Palash, A. R. Dziubyk, I. B. Khomych, Yu. V. Fedyk, "Osoblyvosti zvarnosti stali 30KhHSA" ["Welding Features of 30HGSA Steel"], Scientific Bulletin of UNFU, vol.27, issue 9, pp. 68-72, 2017. [in Ukrainian].

[4] A. Dzyubyk, et al., "Comprehensive approach to training specialists in the area of engineering education", Ukrainian Journal of Mechanical Engineering and Materials Science, vol. 6, no. 1, pp. 39-46, 2020.

[5] A. R. Dziubyk, I. B. Khomych, Metaly ta zvariuvannia $v$ budivnytstvi [Metals and welding in civil engineering]. Drohobych, Ukraine: Posvit Publ., 2018. [in Ukrainian].

[6] V. M. Palash, Metaloznavchi aspekty zvarnosti zalizovuhletsevykh splaviv [Metallurgical aspects of weldability of ferrocarbon alloys]. - Lviv, Ukraine: KINPATRI LTD Publ., 2003. [in Ukrainian].

[7] M. Kh. Shorshorov, V. V. Belov, Fazovyye prevrashcheniya i izmeneniye svoystv stali pri svarke. Atlas [Phase transformations and changes in the properties of steel during welding. Atlas]. Moscow, Russia: Nauka Publ., 1972. [in Russian].

[8] V. N. Volchenko, et al., Teoriya svarochnykh protsessov [Theory of welding processes]. Moscow, Russia: Vysshaya shkola Publ., 1988. [in Russian].

[9] A. R. Dziubyk, V. M. Palash, V. I. Pankiv, "Pidvyshchennia efektyvnosti zvariuvannia stykiv truboprovodiv" ["Improving the efficiency of welding pipe joints"], Scientific Herald of Lviv Polytechnic National University, no. 702, pp. 88-91, 2011. [in Ukrainian].

[10] A. Dzyubyk, V. Palash, I. Khomych, S. Hrynus, "Optimization of Welding Modes for High-Strength Low-Alloy Domex 700 Steel”, Ukrainian Journal of Mechanical Engineering and Materials Science, vol. 3, no. 2, pp. 47-54, 2017.

[11] A. R. Dzyubyk, "Impact Toughness of Welded Joints on 34KhN2MA Steel Produced from Electrodes with Various Phase Compositions", Materials Science, vol. 56, pp. 203-209, 2020.

[12] Tekhnolohyia elektrycheskoi svarky plavlenyem [Electric fusion welding technology], B. Ye. Paton, Ed. Moscow, Russia: Mashynostroyeniye Publ., 1977. [in Russian].

[13] A. R. Dziubyk, I. B. Nazar, R. V. Palash, Pidvyshchennia efektyvnosti zvariuvannia mahistralnykh truboprovodiv pry yikh ekspluatatsii ta remonti [Improving the efficiency of welding of main pipelines during their operation and repair]. Lviv, Ukraine: Spolom Publ., 2013. [in Ukrainian].

[14] B. S. Kasatkin, V. M. Prokhorenko, Y. M. Chertov, Napryazheniya i deformatsii pri svarke [Welding stresses and strains]. - Kyiv, Ukraine: Vyshcha shkola Publ., 1987. [in Russian].

[15] R. M. Kushnir, M. M. Nykolyshyn, V. A. Osadchuk, Pruzhnyi ta pruzhno-plastychnyi hranychnyi stan obolonok z defektamy [Elastic and elastic-plastic boundary state of shells with defects]. Lviv, Ukraine: Spolom Publ., 2003. [in Ukrainian].

[16] A. Dziubyk, et al., "Zabezpechennia tekhnolohichnoi mitsnosti zvarnykh stykiv obsadnykh trub" ["Ensuring the technological strength of welded joints of casings"], Avtomatyzatsiia vyrobnychykh protsesiv $u$ mashynobuduvanni ta pryladobuduvanni, vol. 50. pp. 94-102, 2016. [in Ukrainian].

[17] Spravochnik svarshchika [Welder's Handbook], V. V. Stepanov, Ed. Moscow, Russia: Mashynostroyeniye Publ., 1982. [in Russian].

[18] ESAB «Welding materials». Wires for welding MIG/MAG. [Online]. Available: https://www.esab.ru/ru/ru/products/filler-metals/mig-mag-wires-gmaw/index.cfm/. Accessed on: September 30, 2020. 